\title{
Effect of different methods of hygiene on the color stability of extrinsically pigmented facial silicone
}

Yasmin Morais Cabral ${ }^{1}$, Aldiéris Alves Pesqueira² ${ }^{2}$ Amália Moreno ${ }^{3}$, Marcelo Coelho Goiato ${ }^{2}$, Marcela Filié Haddad ${ }^{4}$

DDS, Department of Restorative Dentistry, Faculty of Dentistry, Federal University of Alfenas (UNIFAL-MG), Alfenas - MG, Brazil.

2 DDS, MSc, PhD, Department of Dental Materials and

Prosthodontics, Aracatuba Dental School, São Paulo State University (UNESP), Araçatuba - SP, Brazil.

${ }^{3}$ DDS, MSc, PhD, Department of Oral Surgery, Pathology and Clinical Dentistry, School of Dentistry, Federa University of Minas Gerais (UFMG) Belo Horizonte MG, Brazil

${ }^{4}$ DDS, MSc, PhD, Department of Restorative Dentistry, Faculty of Dentistry, Federal University of Alfenas (UNIFAL-MG), Alfenas - MG, Brazil.

Corresponding author: Marcela Filié Haddad

Department of Restorative Dentistry and Prosthodontics, Faculty of Dentistry, Federal University of

Alfenas (UNIFAL-MG)

Rua Gabriel Monteiro da Silva, 700, Centro, Alfenas - MG, Brazil CEP: 37.130-000

Phone / FAX: (35) 3299-1464

e-mail:marcela.haddad@unifal-mg.edu.br

Received: October 02, 2017

Accepted: March 28, 2018
Aim: Evaluate the color stability of facial silicone pigmented extrinsically under the influence of the hygiene process. Methods: 160 samples were prepared and divided into 8 groups ( $n=20)$ according to the pigmentation technique used: Group 1: Colorless silicone; Group 2: Pigmented exclusively with oil ink; Group 3: Pigmented with oil ink + opacifier; Group 4: Colorless, applying Prime; Group 5: Pigmented with oil ink covered with Prime; Group 6: Pigmented with oil ink + opacifier and covered with Prime; Group 7: Pigmented with oil ink diluted in Prime; Group 8: Pigmented with oil ink + opacifier diluted in Prime. Then the samples were distributed into two subgropus ( $n=10)$ : 1: neutral soap and 2: $1 \%$ hypochlorite solution. The color readings occurred in the initial period and 60 days after the hygiene procedures. For this, it was used a spectrophotometer reflection and CIE-Lab program. The data was tabulated and submitted to analysis of variance (ANOVA) followed by Tukey test $(p<0.05)$. Results: The groups of samples disinfected with soap showed significantly lower color change values than those presented by the samples disinfected with hypochlorite. The best results were presented by the group of samples pigmented with oil ink diluted in prime and sanitized with neutral soap ( $\Delta E=1.21$, without opacifier and $\Delta E=0.82$, with opacifier). Conclusions: The association of oil ink diluted in prime and hygiene technique with soap promotes the lower color change of facial silicone pigmented extrinsically.

Keywords: maxillofacial prosthesis, prosthesis coloring, disinfection 


\section{INTRODUCTION}

Losses in the maxillofacial region are very embarrassing to the patients because they affect a region of the body so important for the interpersonal relationship, where there are contained organ of the senses, necessary for the interaction of the individual with the neighbor and with the environment. Thus, the loss of such organs often leads mutilated individuals to social exclusion. Maxillofacial prostheses aim to rehabilitate individuals who have suffered loss of structures in the maxillofacial region and that can not be surgically corrected, restoring lost esthetics and partially restoring function'?

The material of choice for making these prostheses is facial silicone, which is available in the market in colorless form and must be pigmented in order to mimic the patient's skin. The pigmentation of maxillofacial prostheses is carried out basically by the use of powdered or oil-based pigments associated or not with opacifiers².

There are two pigmentation techniques: The intrinsic technique, in which the pigments are added to the silicone prior to their polymerization in order to provide an uniform color base; and the extrinsic one, which consists of the characterization of the prostheses through the application of a thin layer of paint on the surface of the pigmented silicone that is intrinsically and already polymerized, in order to reproduce spots and small vessels present in the skin ${ }^{3}$.

Using these two techniques of pigmentation combined with the technical and artistic skill of the professional and considering the advancement of materials available for making maxillofacial prostheses, it is possible to obtain satisfactory aesthetic results, however, such results can not be maintained for the long term, since the prostheses undergo color changes in a short period of time, implying the need for retouching of extrinsic pigmentation or even making a new prosthesis².

It is a consensus in the literature that the main causal factor for the color change of maxillofacial prostheses is the exposure to climatic intemperatures (temperature variation, humidity and ultraviolet radiation exposure). However, clinically, it is possible to notice changes in the extrinsic pigmentation pattern due to the patient's constant handling of the prosthesis and its exposure to the hygiene process with different substances and techniques. Deficiency in hygiene of facial prostheses contributes to the underlying tissues being susceptible to infections. Thus, it is of fundamental importance to perform the disinfection of the prostheses to maintain the health of the tissues. However, one should keep in mind the possible changes that this disinfection may cause in the physical properties of facial silicone $e^{4}$.

Maxillofacial prostheses hygiene is little explored in the literature in clinical studies. There are researches that evaluate the action of substances commonly used for complete dentures hygiene (such as neutral soap ${ }^{2,49}$, hypochlorite ${ }^{7}$, chlorhexidine $^{5}$, effervescent tablets ${ }^{2,48,9}$, ethanol $^{6}$, microwave energy ${ }^{7}$ and plant extracts ${ }^{5}$ ) and the methods of hygiene (immersion ${ }^{2,4-6,8,9}$ or friction ${ }^{2,4-6,7-9}$ ) on physical properties of non-pigmented or pigmented intrinsically with different substances (makeup powders $^{8,10}$, ceramic pigments $s^{8,10,11}$, oil paint ${ }^{1}$ and/or opacifiers ${ }^{9}$ ) used in the manufacture of facial prostheses. 
The literature presents studies that evaluate the amount of pigment boundary that can be used for the intrinsic pigmentation of facial silicones ${ }^{12}$; which pigments are more stable chromatically, what physical properties of the silicone can be altered from the addition of pigments, what changes in optical, mechanical and physical properties occur in the pigmented silicone under the influence of changes in temperature, humidity and disinfection procedures. In addition, it is important to note that there is a strong correlation between the number of species and the number of species that can be identified. However, more information is needed contemplating extrinsic pigmentation, which is still performed empirically and artistically in clinical practice. Thus, the aim of this study was to evaluate the color stability of facial silicone pigmented extrinsically under the influence of the hygiene process.

The work hypothesis is that the different techniques of extrinsic pigmentation and hygiene procedures cause different discoloration patterns of facial silicone.

\section{MATERIAL AND METHODS}

Silastic MDX4-4210 (Dow Corning Corporation, Midland, MI, EUA) is a material used to make maxillofacial prostheses and was used to fabricate 160 specimens, that was divided in 8 groups ( $\mathrm{n}=20$ ) acoording the pigmentation, as shown in the Table 1.

A metallic cylindrical matrix (30-mm diameter, 3-mm thick) was used to obtain the specimens ${ }^{2}$. The silicone were weighed using a precision digital scale (BEL Analytical Equipments, Piracicaba, Brazil). The opacifier weight was equivalent to $0.2 \%$ of the total weight of the silicone ${ }^{11}$. The silicone was manipulated according to manufacturer's instructions, on a glass plate until a homogeneous mixture was obtained.

The silicone was then inserted in the master mold, and the excess was removed with a spatula to maintain a regular thickness. Silastic MDX4-4210 material was confined in the matrix with the external surface exposed to the environment for 3 days, according to the manufacturer's instructions. The material is partially cured after 24 hours, allowing its handling, but final cure following the release of formaldehyde occurs within approximately 3 days, according to the manufacturer ${ }^{13}$. After this period, each specimen was carefully removed from the metallic matrix $x^{2,9,14}$ and the extrinsic pigmentation procedure started.

The samples were pigmented according the division groups presented in Table 1, using oil paint (Color baked siena - Gato Preto, Sorocaba, SP, Brazil); Titanium dioxide opacifier (Naturativa, Araçatuba, SP, Brazil) and DC 1205 Prime (Dow Corning Corporation, Midland, MI, EUA).

Table 1. Test groups.

\begin{tabular}{ll}
\hline Group & Pigmentation \\
\hline 1 & Colorless \\
\hline 2 & Oil paint \\
\hline 3 & Oil paint + Opacifier \\
\hline 5 & Prime \\
\hline 6 & Oil paint + Prime \\
\hline 7 & Oil paint + Opacifier + Prime \\
\hline 8 & Oil paint diluted in prime \\
\hline
\end{tabular}


A protocol for extrinsic pigmentation was not found in the literature, so the techniques used in the present study were developed from pilot studies and varied according to the group, as explained below:

- Group 2, pigmented exclusively with oil paint, a thin layer of paint was applied on the surface of the samples with the aid of a flat brush, drying was expected and a new layer was applied.

- Group 3, which associated ink and opacifier, initially a portion of the ink was weighed on a precision digital scale and $0.2 \%$ (by weight) of opacifier was added to this portion. The two materials were mixed and the blend was applied on the surface of the samples in two layers as discussed above.

- Group 4, which received application exclusively of Prime, a layer of Prime was applied on the surface of the samples with the aid of a flat brush, drying was expected and a new layer was applied.

- Group 5, the same exposed paint technique was used for group 2, and after drying the two layers of paint, 2 layers of prime were applied, as shown for group 4.

- Group 6, the same painting technique presented for group 3 was used and, after drying of the second layer of the paint and opacifier mixture, two layers of prime were applied, as shown for group 5.

- Group 7, which consisted of mixing the paint to prime, initially a portion of the paint was weighed on a precision digital scale and $0.2 \%$ (by weight) of Prime was added. These two substances were mixed and applied in two layers on the surface of the samples, as shown for all pigmented groups presented above.

- Group 8, initially, a portion of the ink was weighed on a precision digital scale and $0.1 \%$ (by weight) opacifier and $0.1 \%$ (by weight) prime were added. The substances were mixed and applied on the surface of the samples in two layers, as already explained for all the pigmented groups presented previously.

All the test specimens obtained were submitted to initial color analysis by means of a Visible Ultraviolet Reflection Spectrophotometer, Model UV-2450 (Shimadzu, Kyoto, Japan). To perform this test, each sample was positioned in a holder which was positioned in the spectrophotometer and the color reading occurred in the central portion of the sample. The use of this holder guarantees that all samples are placed in the same position and that the same sample receives the initial and final color reading also in the same location (in its central portion). The color alterations were calculated using the CIE L*a*b* system, established by the Commission Internationale de l'Eclairage $-\mathrm{CIE}^{2,9}$. This system allows calculation of the mean value of $\mathrm{E}$ (color variation) between two readings by the formula:

$$
\Delta \mathrm{E}=\left[(\Delta \mathrm{L})^{2}+(\Delta \mathrm{a})^{2}+(\Delta \mathrm{b})^{2}\right]^{1 / 2}
$$

After the initial color test, all specimens were stored in a black box without light'2,9,14. The specimens were disinfected three times per week for 2 months ${ }^{2,9,14}$ after reading the initial color.

All samples were submitted to the hygiene procedures. Half of them was sanitized with neutral soap (Johnsons Baby, Johnson \& Johnson, São José dos Campos, SP, Brazil), and the other half disinfected with $1 \%$ hypochlorite (Musgo, Alfenas, MG, Brazil). 
The specimens were cleaned with neutral soap and rubbed with the fingertips for 30 seconds, then rinsed with water for 30 seconds2, 2,14 . The specimens were immersed in a solution of $1 \%$ hypochlorite for 10 minutes and rinsed in running water $2,9,14$.

After simulated hygiene procedures, a new color analysis was performed ${ }^{2,9,14}$.

The color change $(\triangle \mathrm{E})$ values were analyzed by two-way ANOVA, and means were compared by Tukey's test $(p<0.05)$.

\section{RESULTS}

The results obtained are shown in Tables 2 and 3.

It was observed that the Pigmentation and Disinfectant factors, associated or not, produced a statistically significant difference $(P<0.0001)$ in the color change of facial silicone samples (Table 2).

Table 2. Analysis of variance (ANOVA) two factors.

\begin{tabular}{lccccc}
\hline Variation Factors & gl & SQ & QM & F Value & P Value \\
\hline Pigmentation & 7 & 13286,001 & 1898,000 & 315,706 & $<0,0001^{*}$ \\
\hline Disinfectant & 1 & 8848,601 & 8848,601 & 1471,840 & $<0,0001^{*}$ \\
\hline Pigmentation x Disinfectant & 7 & 6035,203 & 862,172 & 143,410 & $<0,0001^{*}$ \\
\hline Error & 144 & 865,718 & 6,012 & & \\
\hline Total & 159 & 29035,524 & & & \\
\hline$* P<0,05$ denotes significant statisti
\end{tabular}

Table 3 shows the mean values and standard deviation of color change of the facial silicone samples for each group evaluated. It is verified that all the samples, pigmented or not, presented color change $(\Delta \mathrm{E}>0)$, after hygiene procedure. The groups of samples disinfected with soap had lower color change values, statistically significant $(P<0.05)$ compared to disinfection with hypochlorite, with the exception of groups 1 and 4 that did not present a statistically significant difference between neutral soap and hypochlorite.

Table 3. Mean values of color change $\Delta \mathrm{E}$ (Standard Deviation) of facial silicone samples for each technique of pigmentation and disinfectant used.

\begin{tabular}{lcc}
\hline \multirow{2}{*}{ Pigmentation } & \multicolumn{2}{c}{ Color change $-\Delta \mathbf{E}$} \\
\cline { 2 - 3 } Colorless & Neutral Soap & Hypochlorite \\
\hline Oil Paint & $1,92(0,76) \mathrm{Aa}$ & $5,42(2,02) \mathrm{Aa}$ \\
\hline Oil paint + Opacifier & $29,89(2,99) \mathrm{Ba}$ & $35,43(8,56) \mathrm{BDb}$ \\
\hline Colorless + Prime & $11,64(0,35) \mathrm{Ca}$ & $35,98(0,84) \mathrm{Cb}$ \\
\hline Oil paint + Prime & $3,42(1,33) \mathrm{ADa}$ & $4,70(1,10) \mathrm{Aa}$ \\
\hline Oil paint + Opacifier + Prime & $10,45(0,48) \mathrm{CEa}$ & $32,38(1,00) \mathrm{BCb}$ \\
\hline Oil paint diluted in Prime & $6,66(0,22) \mathrm{DEa}$ & $24,88(1,88) \mathrm{Eb}$ \\
\hline Oil paint + Opacifier diluted in Prime & $1,21(0,60) \mathrm{Aa}$ & $28,96(0,27) \mathrm{Db}$ \\
\hline
\end{tabular}

*Means followed by the same capital letter in the column and the same lowercase letter in the row do not differ at the $5 \%$ level of significance $(P<0.05)$ by the Tukey test. 
The lowest $\Delta \mathrm{E}$ values were presented by the groups of oil paint pigmented samples diluted in prime and disinfected with soap $(\Delta \mathrm{E}=1.21$, without opacifier and $\Delta \mathrm{E}=0.82$, with opacifier), being statistically significant $(P<0,0001)$ to the other groups, and without significant statistical difference $(P>0.05)$ of the respective colorless control groups. In addition, the oil-pigmented samples in combination of primer and opacifier presented lower color change value $(\Delta E=6.66)$ statistically significant $(P=0.001)$, compared to the oil-pigmented samples combined with the use Opacifier only $(\Delta \mathrm{E}=11.64)$.

\section{DISCUSSION}

The material of choice for the facial prostheses manufacture is silicone. It needs to be pigmented to mimic the patient's skin characteristics. In addition, it is known that deficiency in hygiene of facial prostheses contributes to the underlying tissues being susceptible to infections. Thus, it is fundamental to perform the disinfection of the prostheses to maintain the tissues health. However, materials and techniques used for pigmentation and hygiene can cause changes in the facial silicone $e^{4}$.

The literature is scarce in relation to clinical studies that evaluate different methods of hygiene for maxillofacial prostheses, however, it offers researches that evaluate the interaction between the substances used for hygiene with the base material and the pigments added intrinsically, used to make these prostheses. In this context, several substances and methods of hygiene / disinfection have already been tested (neutral soap $^{2,49}$, chlorhexidine ${ }^{5}$, hypochlorite ${ }^{7}$, effervescent tablets ${ }^{2,4,8,9}$, plant extracts ${ }^{5}$, ethanol $^{6}$, microwave energy ${ }^{7}$ ) and none of them are considered ideal on all aspects (bactericidal potential and preservation of all properties of silicon and pigments). There are no studies evaluating the behavior of pigments added extrinsically to the facial silicone when submitted to the hygienization process.

According to the National Bureau of Standards ${ }^{15}$, the color change is considered to be very small when the $\Delta \mathrm{E}$ is less than 1 . The situation is clinically acceptable if the color change is between 1 and 3 ; And is considered clinically perceptible if $\Delta \mathrm{E}$ is greater than 3 . In the present study, the observed color change varied from 0.82 to 35.98 (Table 3), which allows to affirm that the color change would not be clinically perceptible only for the Groups pigmented with Oil Paint + Opacifier diluted in Prime and Oil Paint diluted in Prime, both disinfected with neutral soap.

The null hypothesis was accepted. It can be observed in Table 2 that Pigmentation and Disinfectant factors, associated or not, produced a statistically significant difference in the color change of facial silicone samples. It is noted that all samples, pigmented or not, showed color alteration after hygiene procedures (Table 3). These results corroborate with those obtained by Goiato et al. ${ }^{16}$, which concluded that even without the disinfection process, the facial silicone undergoes a color change independent of the pigment type and the pigmentation technique used, since the material itself undergoes aging and, consequently, changes in its physical and chemical properties. In addition, other factors may contribute to the silicone color change, such as exposure to solar radiation, temperature variation and humidity. These factors were not considered in the present study as the accelerated aging test was not performed and, as a means of prevention, the samples were stored in a black box while not undergoing tests to reduce their exposure to light ${ }^{17}$. 
It is also known that different substances and disinfection techniques can promote color change in intrinsically pigmented test pieces. Typically, this intrinsic discolouration occurs with aging of the material due to various physico-chemical conditions, such as thermal changes and humidity. Extrinsic factors such as absorption and adsorption of substances may also cause discoloration ${ }^{4,18}$.

In the present study, the groups of samples disinfected with soap presented statistically lower color change values than hypochlorite disinfected groups (Table 3). These different types of substances should be considered as requiring different disinfection techniques. Although the neutral soap hygiene process required friction of the samples, it was less aggressive than the immersion technique used for $1 \%$ hypochlorite. In the study of Goiato et al. ${ }^{16}$, the neutral soap corresponds to the control product because it is considered chemically inert, however, they used intrinsic pigmentation of the silicone. With the results obtained here, it can be considered that the hygiene procedure with neutral soap is less harmful to facial silicone when compared to $1 \%$ hypochlorite even when using extrinsic pigmentation.

It is known that hypochlorite has disinfectant action being able to eliminate bacteria, but also has a bleaching action causing the discoloration where it is made from the reaction of chlorine with calcium hydroxide. This fact justifies the color change of the pigmented samples extrinsically and immersed in $1 \%$ hypochlorite ${ }^{19}$.

Eleni et al.? (2013) evaluated the effect of different disinfecting procedures (microwave exposure and immersion in three solutions, sodium hypochlorite, neutral soap and a commercial disinfecting soap) on the hardness and color stability of two maxillofacial elastomers (An experimental chlorinated polyethylene (CPE) and a commercial polydimethyl siloxane (PDMS)). It was concluded that the disinfection procedures caused alterations in color and hardness of the examined materials. The most suitable disinfection procedure for the PDMS material is microwave exposure, while disinfection with sodium hypochlorite solution is not recommended. The CPE material is suggested to be disinfected with sodium hypochlorite solution and the use of neutral soap is not recommended. Comparing the two materials, the PDMS material is most color stable, while the CPE material presented fewer changes in hardness.

The lowest values of color change were presented by groups of oil-stained pigment samples diluted in prime and disinfected with soap, similar to the respective colorless control groups (Table 3). In addition, oil-pigmented samples in combination of primer and opacifier showed lower values of color change compared to oil-pigmented samples combined with the use of opacifiers alone. It is known that pigment particles can readily separate from the silicone when poorly bonded to the polymer chain of the material and also when exposed to the repeated chemical disinfection process. It is believed that the association between different materials may interfere with the bond formed between pigment and silicone. In studies involving the intrinsic pigmentation of silicone, pigment and opacifier, when associated, can promote the formation of stronger bonding of these pigments to the silicon matrix, avoiding their removal with the disinfection process ${ }^{2,10,11}$. This assertion suggests that the same occurred in the present study when they were associated with oil-based pigment, opacifier and Prime. 
Regarding the use of Prime, when associated with the paint, it preserved the same of degradation, as it was coated with dilute solutions of silane coupling agents and other active ingredients. This fact allows us to believe that, when in use, silicone color protection would be even greater because, in the same way that this prime protects the paint, it also impermeabilizes the silicone, preventing it from absorbing external coloring agents that would degrade the prosthesis.

Based on the results obtained and considering the limitations of an in vitro study, it was concluded that:

The association of oil ink diluted in prime and hygiene technique with soap promotes the lower color change of facial silicone pigmented extrinsically.

\section{ACKNOWLEDGMENTS}

Financial support: Programas Institucionais de Iniciação Científica, Fundação de Amparo à Pesquisa de Minas Gerais (PIBICT - FAPEMIG - Edital PRPPG 021/2015), Alfenas, Minas Gerais, Brasil.

\section{REFERENCES}

1. Haddad MF, Goiato MF, Santos DF, Crepaldi N de M, Pesqueira AA, Bannwart LC. Bond strength between acrylic resin and maxillofacial silicone. J Appl Oral Sci. 2012 Nov-Dec;20(6):649-54.

2. Filié-Haddad MF, Coelho Goiato M, Micheline dos Santos D, Moreno A, Filipe D'Almeida N, Alves Pesqueira A. Color stability of maxillofacial silicone with nanoparticle pigment and opacifier submitted to disinfection and artificial aging. J Biomed Opt. 2011 Sep;16(9):095004. doi: 10.1117/1.3625401.

3. Kiat-Amnuay S, Beerbower M, Powers JM, Paravina RD. Influence of pigments and opacifiers on color stability of silicone maxillofacial elastomer. J Dent. 2009;37 Suppl 1:e45-50. doi: 10.1016/j.jdent.2009.05.004.

4. Goiato MC, Haddad MF, Santos, DM, Pesqueira AA, Moreno A. Hardness evaluation of prosthetic silicones containing opacifiers following chemical disinfection and accelerated aging. Braz Oral Res. 2010 Jul-Sep;24(3):303-8

5. Guiotti AM, Goiato MC, Dos Santos DM, Vechiato-Filho AJ, Cunha BG, Paulini MB, et al. Comparison of conventional and plant-extract disinfectant solutions on the hardness and color stability of a maxillofacial elastomer after artificial aging. J Prosthet Dent. 2016 Apr;115(4):501-8. doi: 10.1016/j.prosdent.2015.09.009.

6. Griniari P, Polyzois G, Papadopoulos T. Color and structural changes of a maxillofacial elastomer: the effects of accelerated hotoaging, disinfection and type of pigments. J Appl Biomater Funct Mater. 2015 Jul 4;13(2):e87-91. doi: 10.5301/jabfm.5000229.

7. Eleni PN, Krokida MK, Polyzois GL, Gettleman L. Effect of different disinfecting procedures on the hardness and color stability of two maxillofacialelastomers over time. J Appl Oral Sci. 2013;21(3):278-83. doi: 10.1590/1679-775720130112.

8. Pesqueira AA, Goiato MC, Dos Santos DM, Haddad MF, Moreno A. Effect of disinfection and accelerated ageing on dimensional stability and detail reproduction of a facial silicone with nanoparticles. J Med Eng Technol. 2012 May;36(4):217-21. doi: 10.3109/03091902.2012.666321.

9. Goiato MC, Haddad MF, Pesqueira AA, Moreno A, dos Santos DM, Bannwart LC. Effect of chemical disinfection and accelerated aging on color stability of maxillofacial silicone with opacifiers. J Prosthodont. 2011 Oct;20(7):566-9. doi: 10.1111/j.1532-849X.2011.00755.x. 
10. Mancuso DN, Goiato MC, Dos Santos DM. Color stability after accelerated aging of two silicones, pigmented or not, for use in facial prostheses. Braz Oral Res. 2009 Apr-Jun;23(2):144-8.

11. dos Santos DM, Goiato MC, Sinhoreti MA, Fernandes AU, Ribeiro PP, Dekon SF. Color stability of polymers for facial prosthesis. J Craniofac Surg. 2010 Jan;21(1):54-8. doi: 10.1097/SCS.0b013e3181c3b58e.

12. Yu R, Koran All, Craig RG. Physical properties of a pigmented silicone maxillofacial materials as a function of accelerated aging. J Dent Res. 1980 Jul;59(7):1141-8.

13. Mancuso DN, Goiato MC, Dekon SFC. Visual evaluation of color stability after accelerated aging of pigmented and nonpigmented silicones to be used in facial prostheses. Indian J Dent Res. 2009 Jan-Mar;20(1):77-80.

14. Goiato MC, Haddad MF, Sinhoreti MA, dos Santos DM, Pesqueira AA, Moreno A. Influence of opacifiers on dimensional stability and detail reproduction of maxillofacial silicone elastomer. Biomed Eng Online. 2010 Dec 16;9:85. doi: 10.1186/1475-925X-9-85.

15. Kelly KL, Judd DB. U.S. Department of Commerce. Color Universal language and dictionary of names National Bureau of Standards; 1976 Dec [access 2018 Feb 20]. 184p. NBS Special Publication 440. Available from: https://nvlpubs.nist.gov/nistpubs/Legacy/SP/nbsspecialpublication440.pdf.

16. Goiato MC, Pesqueira AA, Dos Santos DM, Zavanelli AC, Ribeiro P do P. Color stability comparison of silicone facial prostheses following disinfection. J Prosthodont. 2009 Apr;18(3):242-4. doi: 10.1111/j.1532-849X.2008.00411.x.

17. Siddiquey IA. The effects of organic surface treatment by methacryloxyprophyltrimethoxysilane on the photostability of TIO2. Mat Chem Physics. 2007;105(2-3):162-8. doi: 10.1016/j.matchemphys.2007.04.017

18. Pinel SR, Fairhurst D, Gillies R, Mitchnick MA, Kollias N. Microfine zinc oxide is a superior ingredient to microfine titanium dioxide. Dermatol Surg. 2000 Apr;26(4):309-14.

19. Robinson JG, McCabe JF, Storer R. The whitening of acrylic dentures: the role of denture cleansers Br Dent J. 1985 Oct 19;159(8):247-50. 